\title{
DEMOLITION WASTE OF BRICKS AS RECYCLED AGGREGATES IN CONCRETE MIX AND ENERGY IMPACT.
}

\author{
Abdulghani Monawar*1, Mohammad Haasan Alawi ${ }^{2}$ \\ ${ }^{1}$ Department of Islamic Architecture, College of Engineering and Islamic Architecture, Umm \\ Al-Qura University. Makkah - Saudi Arabia \\ ${ }^{2}$ Civil Engineering Department, College of Engineering and Islamic Architecture, Umm Al- \\ Qura University. Makkah - Saudi Arabia \\ *Corresponding Author's E-mail: ahmonawar@uqu.edu.sa
}

Received: 25 October 2020 Accepted: 05 April 2021

\begin{abstract}
This paper aims to investigate the feasibility of reusing building waste materials as a recycled aggregate (RA) in concrete manufacturing resulting in what is known as recycled aggregate concrete (RAC). The recycling of waste materials in cement concrete has recently become more important and imperative due two main factors, including the continuing growth of building construction, and the urge to find sustainable resources replacement for natural materials. A number of studies and investigations have been carried-out in this field to address the feasibility of reusing recycled buildings waste materials in concrete for new construction and from demolition of existing buildings. However, the present study was experimentally carried-out to evaluate the possibility of reusing crushed clay bricks and cement blocks. Three concrete mix designs with 15, 20, and 30\% of cement were considered. Three types of testing were conducted (slump test, air content, and compressive strength). The outcomes and main findings show that the reuse of crushed clay bricks and cement blocks is feasible, in particular for incorporation in the manufacturing of non-structural concrete element such as barriers and temporary construction. In addition, the reuse of those materials will definitely and effectively contribute to minimizing the consumption of natural materials, save energy and minimize interruption of natural environment, since there are extensively available as waste materials in new construction or by-products of demolishing building.
\end{abstract}

Key words: Compression strength, recycling, clay bricks, cement blocks, building waste materials.

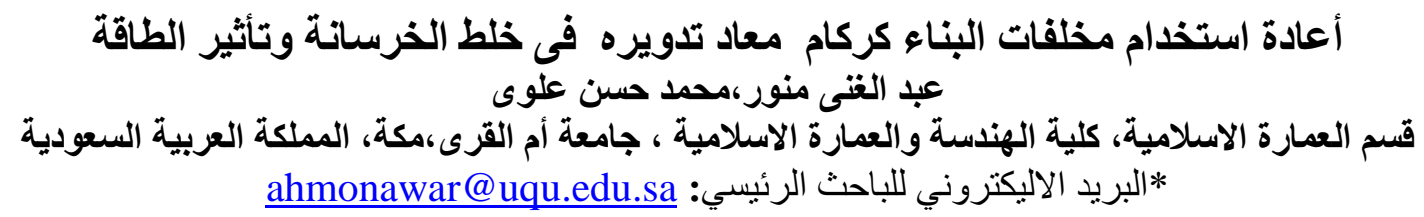




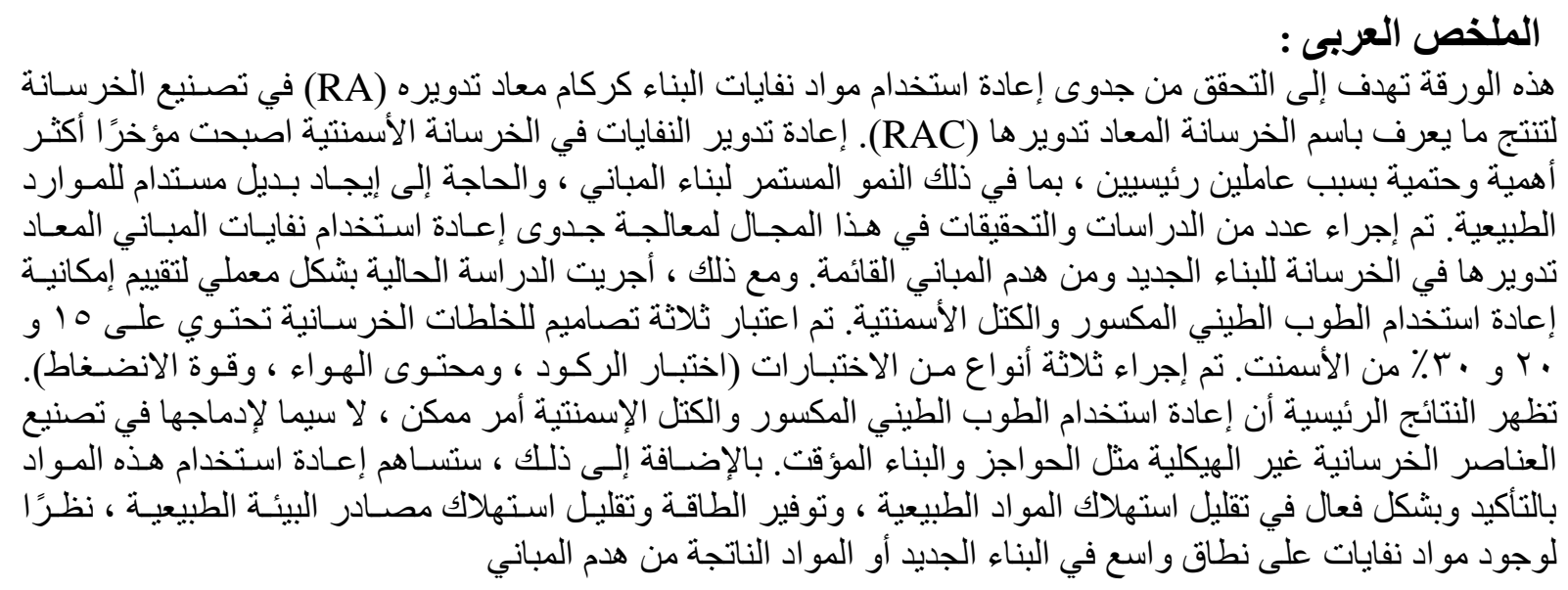

\section{1- Introduction}

Due to nonstop growth of population, technologies, construction the use of natural materials are increasingly demanded and with time it will lead to extinction of the remining natural materials available. One of those natural materials is the natural stones which are extensively used as crushed stones (coarse aggregate) in production of concrete.

Since the past decade until current time, the use of clay bricks and/or cement blocks has been extensively used as major building materials (constructing partitions and walls) in new construction. Yet, most of the contractors exhibit very low efforts in considering the environment and developing methods for minimizing building waste. The use of those building materials in construction, results in considerable quantity of damaged or crashed bricks / blocks as a waste that cannot be used for their genuine purpose.

On the other hand, continuous updates and frequent changes in the building codes and constant widening of the seismic faults across the world necessitate to demolish those buildings that built in the past decades and did not fulfil the existing strength requirements. Various wastes are obtained from demolishing those buildings, including reinforcing steel, concrete, and crashed clay bricks/cement blocks.

The creation of non-decaying waste materials combined with a growing population has resulted in a waste disposal crisis and extinction of natural resources. One solution to this crisis lies in recycling waste into useful products. The recycling of waste products is desirable activity, whether economically motivated or through environmental consideration, or more usually a combination of both. (Woodside et al, 1997). This research investigates the experience of reusing (recycling) of concrete mixtures building materials in any civil engineering structures [3].

In terms of economic and environmental aspects, there are numerous benefits gained. Minimization of waste by recycling will economically benefit for the construction firms. Recycling is useful and helps for overcoming the accumulation of waste materials and cheaper in building construction such as manufacturing of bricks, blocks, barriers, temporary structure, etc. There is an immediate need to study the properties of these materials and the feasibility of its use in association with the standard specifications.

Additional studies were conducted to investigate the engineering feasibility of the use of the bricks waste, (Pitarch etal,2019) investigated the waste of different construction materials including tile ceramic, red clay bricks, and ceramic sanitary ware. It was concluded that a replacement of $30 \%$ weight of coarse aggregate with red clay brick resulted in a reduction of $11 \%$ in the compressive strength for concrete cured for 28 days [1].

Another investigation carried out by (Khalil et al, 2018) to study the mechanical properties of 
self-compacting concrete (SCC) with clay bricks waste aggregate. In general, it was found that a general reduction with various percentages in density, compressive and tensile strength, modulus of elasticity and thermal conductivity [2].

Similar study was also conducted by (Youcef et al, 2017). The obtained results showed that the use of brick waste as coarse aggregate in the concrete may produce a concrete with satisfactory engineering properties. Accordingly, it is clearly that most of researches conducted in this field is limited and still at early stage. Thus, further investigations are necessary and required to fully understand the mechanical properties and behavior of concrete with recycled aggregate and waste of masonry [4].

\section{2- Objectives}

The objectives of this study is to investigate the possibility of reusing clay bricks/cement blocks recycled from construction demolition waste (Fig.1) in any civil engineering application using Portland cement type I, also to produce an economical cement concrete possessing desired/required compressive strength, workability, and percentage of air content in accordance with the strength and serviceability requirements.

The following study program was carried out to attain the previously mentioned objectives:

1- To perform sieve analysis, Specific gravity tests for natural aggregate and red clay blocks and bricks waste.

2- To evaluate the main mechanical characteristics of the fresh and hardened concrete with recycled coarse aggregate from red clay bricks including, slump, compression strength test, and air in fresh concrete.

3- Based on the results of the above testing, the concrete mixes with recycled coarse aggregate are characterised for their possible civil engineering applications.
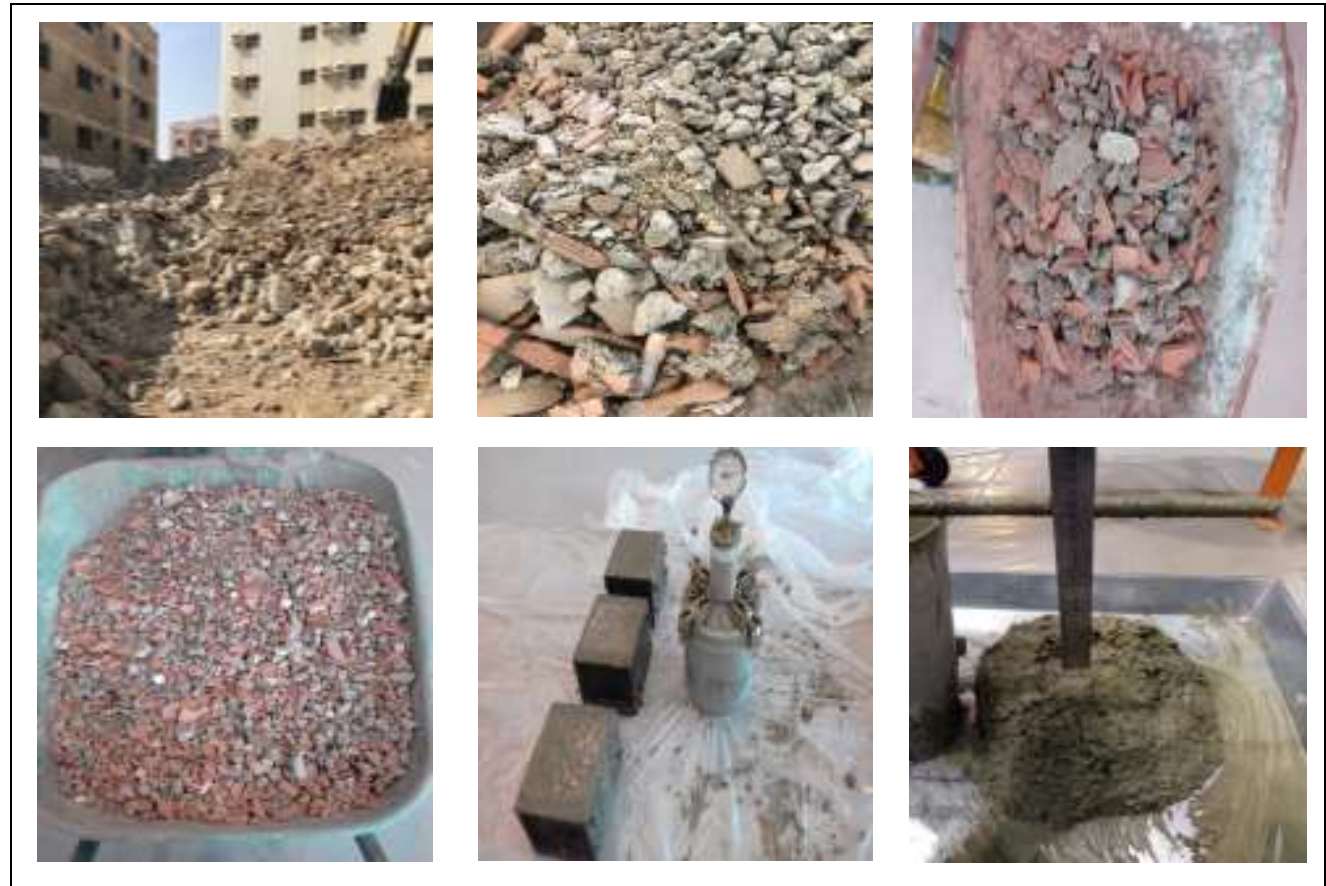

Fig. (1): Concrete mix with recycled construction demolition waste. 


\section{3- Materials}

The materials used in the study are waste of bricks, blocks, mortar, and concrete blocks, natural coarse and fine aggregate, ordinary Portland cement type I, and tap water. The properties of aggregates are as follows in table (1):

Table (1): Material properties

\begin{tabular}{|c|c|c|c|c|c|}
\hline $\begin{array}{c}\text { Waste } \\
\text { Materials }\end{array}$ & c.agg. & $\begin{array}{l}\text { Normal } \\
\text { Concrete }\end{array}$ & c.agg. & $\begin{array}{l}\text { Normal } \\
\text { Concrete }\end{array}$ & f.agg. \\
\hline \multirow{2}{*}{$\begin{array}{c}\text { sieve } \\
\text { analysis }\end{array}$} & & \multirow{2}{*}{$\begin{array}{r}\text { Sieve } \\
\text { analysis }\end{array}$} & & sieve analysis & \\
\hline & & & & \multirow{2}{*}{ sieve size } & \multirow{2}{*}{$\begin{array}{c}\% \\
\text { passing }\end{array}$} \\
\hline \multirow{2}{*}{ sieve size } & \multirow{2}{*}{$\begin{array}{c}\% \\
\text { passing }\end{array}$} & \multirow{2}{*}{ sieve size } & \multirow{2}{*}{$\begin{array}{c}\% \\
\text { passing }\end{array}$} & & \\
\hline & & & & $3 / 8 "$ & 98.9 \\
\hline $1 "$ & 100 & $1 "$ & 100 & no. 4 & 95.0 \\
\hline $3 / 4 "$ & 92.4 & $3 / 4 "$ & 74.4 & no. 8 & 85.8 \\
\hline $1 / 2 "$ & 54.6 & $1 / 2 "$ & 7.5 & No16 & 65.5 \\
\hline $3 / 8^{\prime \prime}$ & 38.1 & $3 / 8^{\prime \prime}$ & 0.8 & No.30 & 38.5 \\
\hline no. 4 & 18.4 & no. 4 & 0.2 & No.50 & 19.8 \\
\hline no. 8 & 10.7 & no. 8 & 0.1 & No100 & 10 \\
\hline no. 200 & 1.4 & no. 200 & 0.1 & 1 20100 & 41 \\
\hline absorption & $10.3 \%$ & absorption & & No.200 & 4.2 \\
\hline Gs bulk & & $=0.91 \%$ & 0.91 & absorption & $3.63 \%$ \\
\hline SSD & 2.239 & Gs bulk SSD & 2.870 & Gs bulk SSD & 2.588 \\
\hline
\end{tabular}

\section{1 - Red Clay Bricks/Cement Blocks}

For a purpose of comparison, both concrete mix designs (natural and recycled coarse aggregate) have approximately a maximum size of $25.4 \mathrm{~mm}$ as shown in (Fig 2).

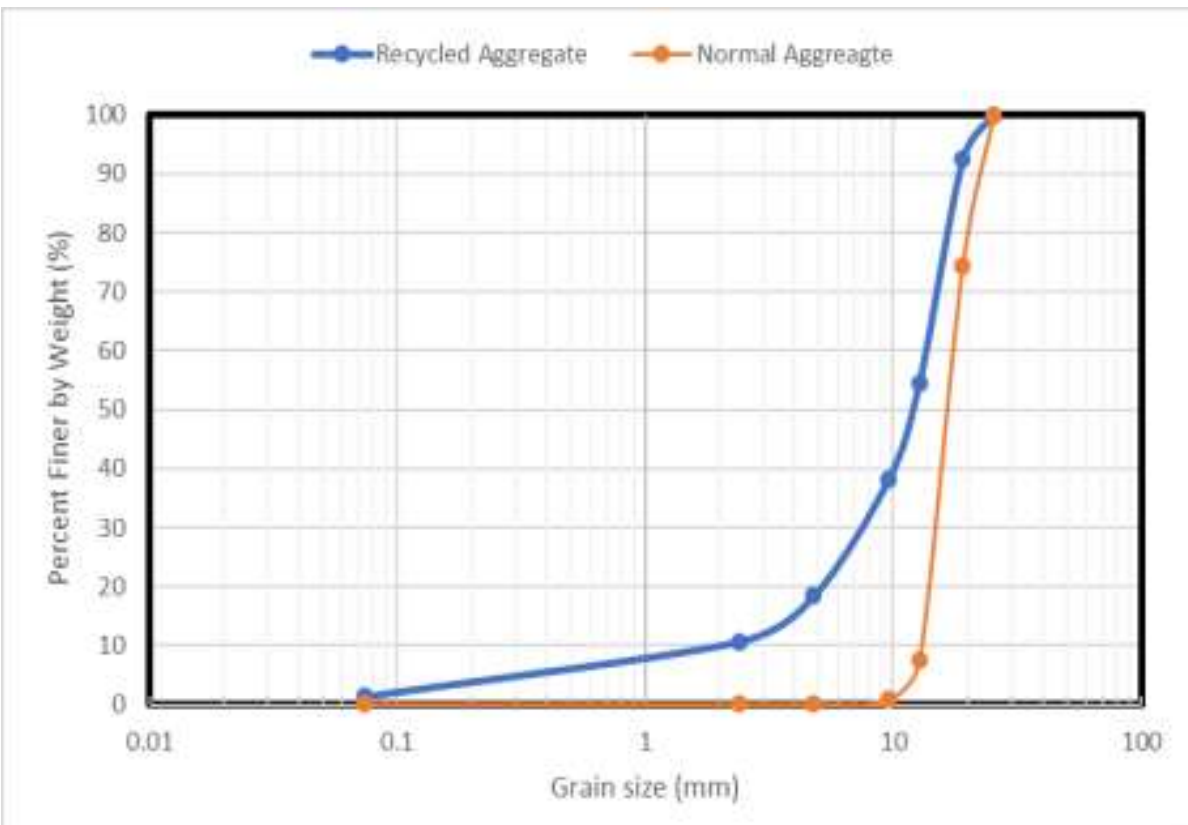




\section{Fig. ( 2 ): Grain size distributions of natural and recycled coarse aggregate}

\section{2 - Concrete Mix Design}

In the current study, only one concrete mix design was investigated comparing to normal one. Table (2) shows the sample test results of the mix design proportions. Waste materials is a concrete contains solid construction waste of consolidated fragment of blocks, bricks and concrete, different percentages of cement and water. Normal material is a usual mix contains natural coarse aggregate, fine aggregate, different percentages of cement and water.

The normal concrete mix has $60 \%$ coarse aggregate $+40 \%$ fine aggregate while waste materials concrete has a mix of $30 \%$ red blocks $+40 \%$ cement blocks $+20 \%$ concrete $+10 \%$ other (sand, mortar).

\begin{tabular}{|c|c|c|c|c|c|c|c|}
\hline No. & $\begin{array}{c}\text { Type } \\
\text { of } \\
\text { Materials }\end{array}$ & $\begin{array}{c}\% \\
\text { of } \\
\text { Cement }\end{array}$ & $\begin{array}{c}\text { W/C } \\
\text { Ratio }\end{array}$ & $\begin{array}{c}\text { Compressive } \\
\text { Strength } \\
\text { Test (Mpa) }\end{array}$ & $\begin{array}{c}\text { Slump } \\
\text { (cm) }\end{array}$ & $\begin{array}{l}\text { Density } \\
\left(\mathrm{Kg} / \mathrm{m}^{3}\right)\end{array}$ & $\begin{array}{c}\text { Air in } \\
\text { Fresh } \\
\text { Concrete, } \\
(\%)\end{array}$ \\
\hline 1 & normal & 15 & 0.5 & 41 & 2 & 2590 & 2 \\
\hline 2 & normal & 15 & 0.6 & 43.0 & 6 & 2620 & 3 \\
\hline 3 & normal & 15 & 0.7 & 38 & 20 & 2660 & 1 \\
\hline 4 & normal & 20 & 0.53 & 41.7 & 6 & 2690 & 1.3 \\
\hline 5 & normal & 20 & 0.6 & 44 & 16 & 2650 & 0.8 \\
\hline 6 & normal & 20 & 0.7 & 39.2 & 23 & 2580 & 0.5 \\
\hline 7 & normal & 30 & 0.4 & 64.0 & 13.5 & 2630 & 1.6 \\
\hline 8 & normal & 30 & 0.45 & 61.0 & 14.0 & 2650 & 1.9 \\
\hline 9 & normal & 30 & 0.5 & 54.6 & 27.5 & 2570 & 0.4 \\
\hline 1 & waste & 15 & 0.95 & 8.5 & 3 & 1960 & 12 \\
\hline 2 & waste & 15 & 1.0 & 24.0 & 13.5 & 2130 & 15 \\
\hline 3 & waste & 15 & 1.2 & 14.5 & 11 & 2130 & 10 \\
\hline 4 & waste & 20 & 0.87 & 19.0 & 5 & 2290 & 5.5 \\
\hline 5 & waste & 20 & 0.90 & 20.0 & 13.5 & 2200 & 3.9 \\
\hline 6 & waste & 20 & 0.95 & 23.5 & 21 & 2150 & 3.2 \\
\hline 7 & waste & 30 & 0.52 & 39.0 & 12.5 & 2360 & 2.5 \\
\hline 8 & waste & 30 & 0.65 & 27.5 & 8.5 & 2320 & 7 \\
\hline 9 & waste & 30 & 0.67 & 37.5 & 15.5 & 2470 & 2.5 \\
\hline
\end{tabular}

\section{4- Analysis and Results}

The output results discuss nature of the examined mixtures with regards to the most common properties that gives concrete its valuable importance as the most widely used building material. Properties under discussion are shown above are workability, mixture density, air in 
fresh concrete, slump test and compressive strength.

Table 2 shows the results for two mixes with different w/c ratio, so we can select one waste concrete mix comparing to normal one with compression strength $\geq 20 \mathrm{Mpa}$, slump results ranges from 9 to $15 \mathrm{~cm}$ and economical.

The selected waste mix is (no.5) the $\%$ of cement is $20 \%$, w/c ratio is 0.9 , c. strength $=20$ Mpa, slump is $13.5 \mathrm{~cm}$, density is $2200 \mathrm{~kg} / \mathrm{m}^{3}$ and air in fresh concrete is $3.9 \%$ comparing to normal mix (no. 5) \% of cement is 20 , w/c ratio is 0.6 , c. strength is $44.8 \mathrm{Mpa}$, slump $=16$ $\mathrm{cm}$, density is $2650 \mathrm{~kg} / \mathrm{m}^{3}$ and air in fresh concrete is $0.8 \%$.

The results of waste mix is acceptable, it could be used in manufacturing of bricks, blocks, barriers, temporary structures etc. The air in fresh concrete for normal mix ranges from 0.4 to $3 \%$ is acceptable comparing to waste concrete mix ranges from $2.5 \%$ to $15 \%$ which is high because of high porosity of recycled aggregates.

\section{5- Recycling Process and Energy Conservation}

Building materials usually consume a huge amount of energy to produce products from their raw resources to their final shape that made them ready to be used in construction industry. The imbedded energy in this industry is considerable and costly by all means to any economy.

Concrete is one of the most common and important material in the construction industry worldwide. It is a needed construction material that an equivalent of one ton of concrete per person is produced every year. The production of a cubic meter of concrete consumes approximately 2775 mega Joules of energy, which is mostly produced from burning crude oil at a rate of 0.37 barrels per cubic meter [5].

In country like Saudi Arabia where energy from natural resources of oil is considered fast and abundant, yet large plans in 2030 National Vision are assigned towards releasing economy dependence on oil and rationalizing the use to conserve this fatal resource from depletion.

Advancement in research for transferring and localizing knowledge associated with alternative passive natural energy is seriously undertaken by different governmental institutions in very progressive speed.

Lack of statistical data and research for local energy consumption associated with building materials industry is noticeable and require further effort from the researchers to document and subject this issue for additional investigation. However, there is no doubt that there is a demand for this materials to meet urban construction development in Saudi Arabia and energy is the master key ruling this industry.

Local municipalities are now dealing with this source in a traditional way, either by using it to level hilly lands or to damp it randomly into landfills. Both methods represent a complete waste of this source of recyclable materials, and if these materials are recycled, they will undoubtedly be a low-cost alternative and support for the construction and real estate development industry in the region.

Recycling notion is an active processes that have a promising future in securing another resource for usable materials from basic first production with less energy involving by recycling process. Researches reveal that almost 30\% of energy is saved from recycling materials according to recycled material in hand [6].

The savings result from the neutralization of a number of multiple operations, i.e. extraction, processing, and transportation, that the process of raw materials usually goes through for enduse material production.

Moreover, a highly cost-effective production with far less environmental pollution impact could be attained when implementing this policy in construction industry field. The research 
in hand demonstrates applicability and practicality of employing this strategy in large scale with concerned local construction industry .

The amount of solid construction waste is enormous due to urban development and construction replacement carried-out on land old for buildings with new ones. Figures $(6 \& 7)$ show demolition waste and illustrate a typical profile of waste amount in the city of Makkah in Saudi Arabia.

Almost $45 \%$ an increase in total waste from year 2018 to 2019 with total amount of (3.07) million tons. This draws an image of intensive development replacement of old buildings and sometimes a new ones that carried out recently in most of the Kingdome cities with new buildings designed to serve different purposes. The quantity of construction waste could be higher in other large cities in the Kingdome of Saudi Arabia [7]. Local development and projects would keep this source needed and available for investment in recycling as a new line of industry in building materials.

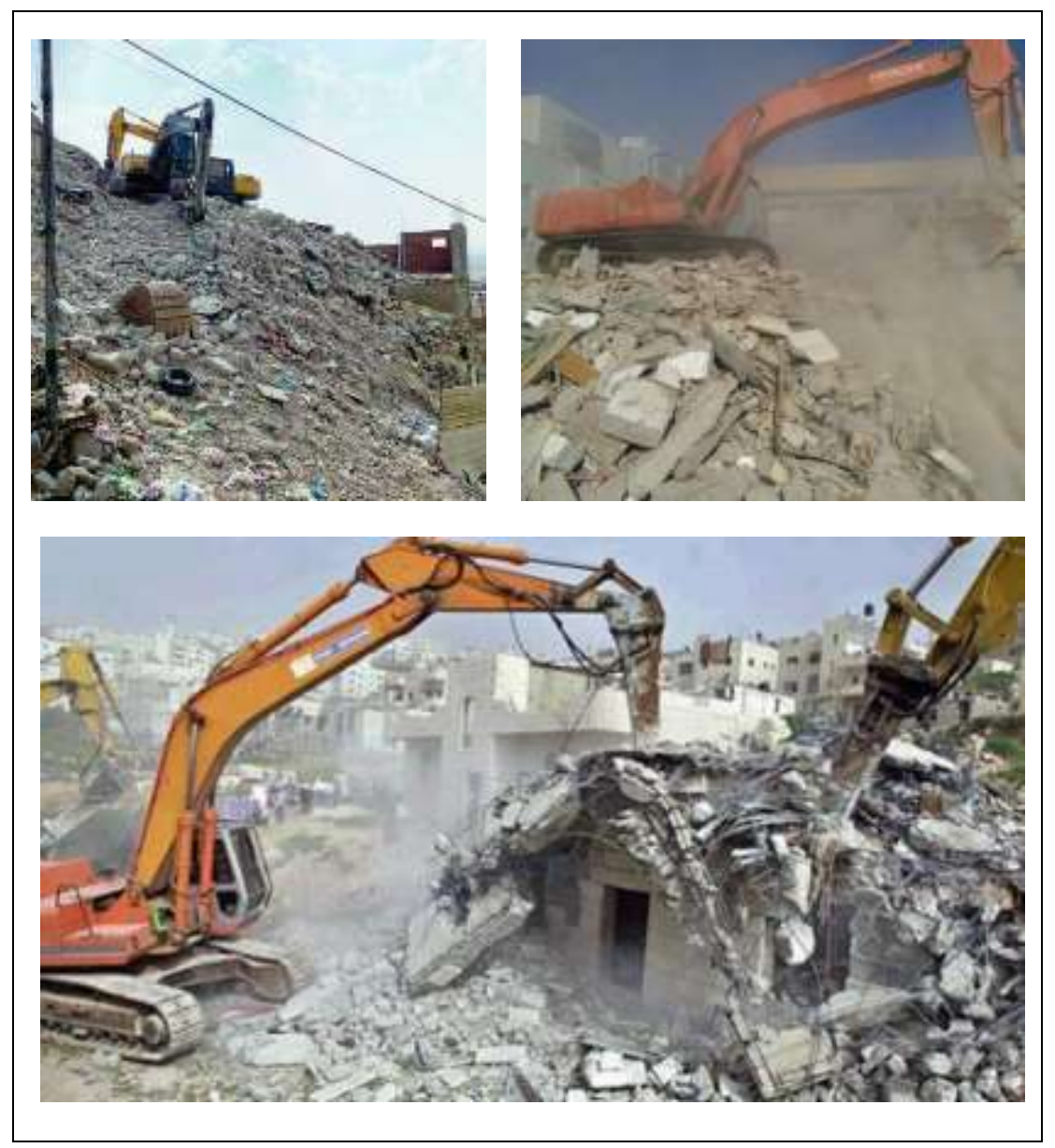

Fig. (6): Construction waste produced by demolition process in the city of Makkah - Saudi Arabia. 


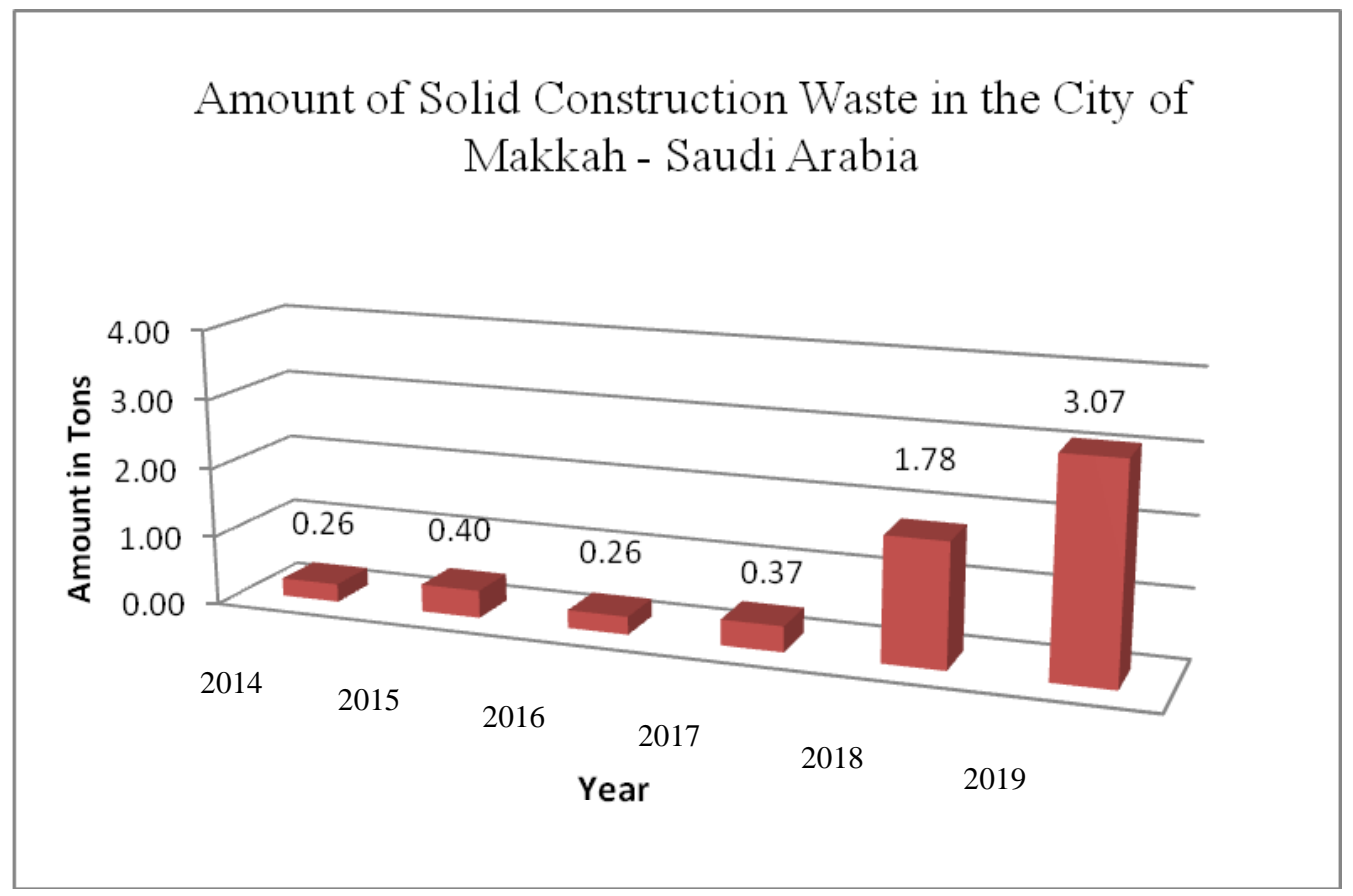

Fig. (7): Amount of solid construction waste in the city of Makkah Saudi Arabia.

\section{6- Global Recycling Trends of Solid Construction Waste Materials}

Construction waste is referred to materials from building demolition that usually damped as a land fill. This material is a mix of solid form concrete, brick and block aggregate resulted from the demolition process. Every year, global urban waste results in approximately (1.3 billion tons) of solid waste, and this percentage is expected to increase to ( 2.2 billion tons) annually by 2025 , where half of this waste is formed from the generated solid building materials [8].

There is an active International movement to reduce negative environmental impact and promote a new opportunities for building material industry to invest and develop in recycling of construction waste.

Worldwide geographical distribution of solid construction waste is based on the markets of the countries that produce a large amount of this waste as a result of high economic development such as Asia, the Pacific, North America, Europe, Latin America and the Middle East. European countries are considered to be the global leaders in developing technology for recycling solid construction waste ${ }^{[9]}$.

Issues associated with investment in recycling is promising economical wise and environmental wise. New opportunities for new industrial lines can be established which will represent an added value to economical environment and local income.

Taking Makkah city as an example, the aggregate cost is (14 SR/Tone) exclude transportation cost. With total amount of 3 million tons of recycled demolition solid waste, the saving would be around (42 million SR) plus other savings return from energy expenditure used to process raw materials [10].

Environment would also be greatly benefitted by recycling industry that make it more clean and undisturbed natural land and keep natural resources preserved for future generation. 


\section{7- $\underline{\text { Conclusion }}$}

The output discussion carried-out above leads to the following conclusions with regards to the possibility and applicability of considering recycling of solid demolition waste and its reutilization in construction industry once more:

1. The demolition solid waste could effectively be replaced natural aggregate in concrete if appropriately recycled according to certain criteria such as grain size and moisture contents, specific gravity, density etc.

2. Performance properties of the concrete produced from recycled demolition solid waste such as c. strength is lower than natural mix (about 30\%) and could be improved.

3. The workability of the mix from recycled materials is not far from the workability from the natural material mix.

4. Air content in the fresh natural mix is less than 3\%. Meanwhile, air content is more presented in the recycled materials mix with a range from 2.5 to $15 \%$ due to the fact of porosity and inconsistency nature of recycled solid aggregate.

5. The compressive strength of recycled aggregate concrete mix is generally acceptable for non-structural purposes. However, the differences between the two sample could be improved by an increase of $10 \%$ cement in the mix.

6. The indication of potential saving in aggregate cost could reach to (43 Millions $\mathrm{SR} /$ year) depends on the amount of total demolition solid waste produced each year.

\section{8- Recommendations}

Recycling material strategy is a practical and effective tool for better utilization of wasting materials worldwide. Construction solid waste is a cheaply available alternative source for construction industry that can minimize cost and refresh local market and local economy with a new industrial production line for securing building materials.

The study carried out has demonstrated a promising results for effective utilization and reproducing building materials without further compromising of quality safety and preserving resources. The recycling industry is a contemporary issue that most of the Nations take it seriously and want to advance in research for creating and implementing solutions that make reuse of this voluble wasted resources economically feasible. .

Saudi Arabia has all the capabilities to make this industry feasible and practical. However, this work needs total collaborations from the government institutions, private sectors, academic and research parties.

Further research effort should be carried-out to investigate the whole industrial prospective associated with this issue and how each part of this industry i.e. waste collections, transportation, processing, and marketing would link to other.

One of the important recommendation is to educate the private sector with huge potentiality in recycling industry and provide all technical and administration support for this industry to see it happen and flourish. 


\section{REFERENCES}

[1] Pitarch, A.M., Reig, L., Tomas, A.E. and Lopez, F.J, “Effect of Tiles, Bricks and Ceramic Sanitary-Ware Recycled Aggregates on Structural Concrete Properties, ” Journal of Waste and Biomass Valorization, Volume 10, 2019, pp. 1779-1793.

[2] Khalil1, Wasan I. and Al-Daebal, Thaer A., "Engineering Properties of Sustainable Self compacting Concrete with Clay Bricks Waste Aggregate," Kufa Journal of Engineering, Volume 9, No. 3, 2018, pp. 223-237.

[3] Woodside A.R., Woodward W.D.H. and Akbulut H., "The Enhancement of Stone Mastic Asphalt by the Use of Cellulose fibre", Proceedings of the $2^{\text {nd }}$ European Symposium on performance and Durability of Bituminous Materials, Edited by J.G. Cabrera, Leeds, April, 1997.

Youcef, Bahia, Et al, 2017. "Recycling of Brick Demolition Concrete Aggregate Wastes [4] Concrete", International Multidisciplinary Scientific Geo Conference, SGEM. - Sofia, Vol17 DOI: 10.5593/segm 2017/62.

[5] Francesco Guidetti, 2017. Energy consumption in production of concrete. https://www.geoplastglobal.com/en/blog/energy-consumption-production-of- concrete.

[6] EUROSTAT, 2017. Manual on waste statistics - A handbook for data collection on waste generation and treatment Generation of Waste Annual Report.

Administration for Environment, Municipality of the holy Capital of Makkah, General [7] 2019. "Solid Construction Waste Section ". Annual statistical report

[8] Kaza, Silpa; Yao, et al, 2018. What a Waste 2.0 : A Global Snapshot of Solid Waste Management to 2050. Urban Development;. Washington, DC.

[9] Bjegove., D., et al, 2010 “ Ecological Aspects of Concrete Production”, $2^{\text {nd }}$ Int. Conf. on Sustainable Construction Materials and Technologies, Ancona, Italy.

[10] STB, Saudi Transport Baton Company, 2018. Annual statistical Report. Jeddah- Saudi Arabia. 